\title{
International symposium on trichomonads and trichomoniasis
}

\author{
Report of the international symposium on trichomonads and trichomoniasis held in Prage from 2 to 7 \\ July 1985
}

The international symposium on trichomonads and trichomoniasis, a satellite meeting of the Congress of Protozoology, was held in Prague from 2 to 7 July 1985 . The symposium was attended by 124 delegates from 22 countries, the chief organiser being Dr J Kulda (Czechoslovakia) from the department of parasitology, Charles University.

The opening ceremony took place at the Carolinum, the ancient quarter of the Charles University founded by King Charles IV. Professor Jiri Vavra, vice chairman of the department of parasitology, Charles University, opened the meeting and welcomed all the delegates. The scientific sessions took place at the conference centre of the Czechoslovak Society of Science and Technology.

The first session was opened by the chairman, Professor B M Honigberg (United States of America), who discussed the cytology, ultrastructure, and evolutionary relations of trichomonads. Dr J Kulda gave a detailed account of the basic structure and function of the trichomonad cell.

The subject of true cysts among trichomonads was discussed, it being stressed that true cysts are absent in most species. Professor L S Diamond (USA) discussed the importance of in vitro cultivation in diagnosis and in elucidating the nutritional requirements and the metabolic pathways of these parasites. Dr John Ackers (United Kingdom) spoke about the immunological and biochemical procedures in the identification of the trichomonad genera, species, and strains. The importance of sensitive tests such as enzyme linked assays, monoclonal antibody assays, and

Address for reprints: Dr J John, Department of Genitourinary Medicine, St Mary's Hospital, Dunstable Road, Luton, Bedfordshire LU1 1BE

Accepted for publication 13 February 1986 indirect fluorescent antibody tests were considered to hold great promise for the future.

The progress in our knowledge of the biochemistry of trichomonads had advanced considerably since the international symposium of trichomonads and trichomoniasis held in 1981. Dr M Muller (USA) gave an excellent review lecture on "the hydrogenosomes". The advances in biochemistry should provide much information towards understanding the biology of the parasite and towards the development of new treatment regimens.

The session on immunology, pathogenicity, and the study of laboratory models, chaired by Dr J John (UK) was opened with a review lecture from Professor B M Honigberg on trichomonal immunology. He pointed out that there were still large gaps in our knowledge of the antigenic properties, host response, and virulence mechanism of the organism. The importance of developing further in vitro and in vivo systems, such as cell cultures and new animal models, for studies of pathological changes was stressed by other speakers. Dr L G Keith (USA) emphasised the role of Trichomonas vaginalis as a "vector" in transporting pathogenic organisms in the human genital tract, and its possible role in conditions such as pelvic inflammatory disease. Another interesting new topic discussed at the symposium was the use of a vaccine lactobacillus vaccine, Solco Trichovac, - in preventing trichomoniasis. Some authors reported that in about $90 \%$ of cases, the vaccine protected the patients for one to two years. In view of the lack of understanding of the status of the micro-organisms used in the manufacture of the vaccine and its mode of action, however, it was concluded that the generalised use of the vaccine would have to wait until further work was done.

The session on epidemiology, clinical manifestations, and pathology, chaired by $\mathrm{Dr}$ J John, discussed the various aspects of trichomoniasis that are of great importance to the practising clinician. Dr A McMillan (UK) reviewed the epidemiology of human trichomoniasis and pointed out that there had been a reduction in the incidence of this infection in some countries, such as the United Kingdom. It was suggested that one of the important factors responsible for the lower incidence had been the widespread use of metronidazole in the United Kingdom. Dr J John discussed the clinical manifestations of human trichomoniasis, especially the possible role of $T$ vaginalis in causing infertility and the common association of the parasite with cervical carcinoma. He emphasised that this apparent relation needed further study. Dr P K Gupta (USA) outlined the pathological changes in human trichomoniasis, stressing that the finding of a non-inflammatory response in asymptomatic trichomoniasis paralleled the inflammatory response in symptomatic cases. Dr W A Gardner (USA) in his presentation on histopathological correlates of trichomoniasis in men, described the invasive nature of the parasites by showing them in the parenchyma of the prostate. The members of the symposium stressed the necessity of further studies of the pathological changes accompanying the infection and of the virulent strains in cervical cancer. Extraurogenital trichomoniasis in man was discussed in detail by Professor Juri Teras (Union of Soviet Socialist Republics), who suggested that Pentatrichomonas hominis possibly causes diarrhoeae and that Trichomonas tenax may cause respiratory problems.

The symposium also discussed the clinical and experiemental aspects of chemotherapy and the mode of action of the drugs used in the treatment of trichomoniasis. Dr J John discussed the advances in treatment of human trichomoniasis with 5-nitroimidazoles, and Dr D I Edwards (UK) discussed their mode of action. The members of the meeting stressed the need for new drugs; the antitrichomonal activity of some non-toxic sugar 
hydrazones was discussed. Drug resistance in the treatment of trichomoniasis was reviewed by Jaroslav Kulda's team from Czechoslovakia, and the metabolic properties of metronidazole-resistant strains of $T$ vaginalis was discussed. The discussions on chemotherapy and drug action showed that tremendous progress had been made in the understanding of the mode of action of the 5-nitroimidazoles. The members of the symposium emphasised the importance of monitoring susceptibility levels to 5nitroimidazoles of $T$ vaginalis from various centres.

Professor B M Honigberg, in the closing session of this five day meeting, presented a summary of the symposium proceedings. It was suggested that the next international symposium on trichomoniasis should be held in Edinburgh in 1989. 